\title{
Innovator's Innovative Genetic Model: From Biological to Social Perspective
}

\author{
Kumchol Ri ${ }^{1,2}$, Yanqing Wang ${ }^{1,}$, Xiran Zhang ${ }^{3}$ \\ ${ }^{1}$ School of Management, Harbin Institute of Technology, Harbin, China \\ ${ }^{2}$ Life Science Department, University of Science, Pyongyang, Democratic People's Republic of Korea \\ ${ }^{3}$ School of Computer Science and Technology, Harbin Institute of Technology, Harbin, China \\ Email address: \\ 17bf10093@stu.hit.edu.cn (Kumchol Ri),yanqing@hit.edu.cn (Yanqing Wang),1150240328@stu.hit.edu.cn (Xiran Zhang) \\ ${ }^{*}$ Corresponding author
}

\section{To cite this article:}

Kumchol Ri, Yanqing Wang, Xiran Zhang. Innovator's Innovative Genetic Model: From Biological to Social Perspective. Science Journal of Business and Management. Vol. 6, No. 2, 2018, pp. 38-44. doi: 10.11648/j.sjbm.20180602.12

Received: June 14, 2018; Accepted: July 12, 2018; Published: August 1, 2018

\begin{abstract}
While scientific theories such as genetic engineering and gene editing technology have an impact on the biological field, researchers have gradually been applied the theory of biological genetics to specific fields such as computers, knowledge innovation, and design innovation. Many researchers have shown that innovators have specific characteristics that differ from those of the general population and reported on these factors extensively. However, few studies have been reported to consider these innovator-specific factors as innovative genes and to evaluate innovators. In this study, these characteristics specific to the innovator were considered as the human social genes equivalent to human biological genes and the relevance between them was examined. As results, the biological genetic theory was integrated with the innovative theory and a theoretical model of innovative genetics was proposed based on the concepts of innovative genes and innovative chromosomes. Their roles were also pointed out in the innovative process, along with a model of innovation genes, innovative chromosomes, and innovative education that promote innovators' innovation.
\end{abstract}

Keywords: Innovator, Innovative Gene, Innovative Chromosome, Innovative Genetic Model, Innovative Education

\section{Introduction}

As the driving force of economic growth, innovation has become an important determinant of the competitiveness of an organization, and the improvement of innovative capabilities needs to be preceded by scientific innovation methods [1-3]. With the rapid advancement of basic science research and science and technology, the continuous emergence of new disciplines and interdisciplinary disciplines has greatly promoted the theoretical research of innovation. While scientific theories such as genetic engineering and gene editing technology have been applied to the biological field, nowadays they have been also introduced gradually into other fields. In this regard, many researchers have carried out extensive research on the innovative application of biological genetic theory in other fields [4-6]. Researcher [7] analogized the evolution of technology and the principle of natural evolution, applying genetic principles to the evolutionary path of technology. Kell et al. [1] combined the innovation process with the concept of biological evolution and used the theory of gene mutation and recombination to reveal the process of disruptive innovation. Wang et al. [4] applied genetic engineering principles to the variant design of a stacker crane and proposed a genetic control mechanism for diversified product design innovations. Feng et al. [5] combined the innovative theory with the biological genetics theory on the basis of analyzing the similarities between the innovative process and the forming process of living beings, and constructed a theoretical model of innovative genetics, providing ideas and methods for specific technological innovations. Liu et al. [6] combined product genes concepts with physical information expression process, proposed a product unit genes expression method described into physical units, and created a variant design model based on product genes and physical expression. Like this, many researchers 
have applied the theory of biological genes to specific fields such as computers, knowledge innovation, and design innovation, etc. [3-5].

In recent years, with the in-depth study of the entire innovator and the development of the times, the definition and attributes for innovator have undergone a gradual process of dynamic evolution [7-8]. A comprehensive analysis of previous studies defines as; innovators have a good system of innovative qualities that can create new knowledge, technologies and products by breaking through the original theory, viewpoints, techniques and methods, and contributing to the progress of the society and the development of the times. Many researchers have shown that innovators have specific characteristics that differ from those of the general population and reported on these factors extensively $[1,2,9]$. However, few studies have considered these innovatorspecific factors as innovative genes for evaluating innovators.

These characteristics specific to the innovator were considered as the human social genes equivalent to human biological genes and examined its relevance. As results, the biological genetic theory was integrated with the innovative theory, and a theoretical model of innovative genetics was proposed based on the concepts of innovative genes and innovative chromosomes. It aims at exploring the inherent characteristics of innovators, explaining the associations of these characteristics, and providing a theory that promotes human innovation. The results provided theoretical and technical tools for the development of specific innovations.

\section{Theoretical Background}

\subsection{Innovation}

Innovation, is a topic that never fading charms, and the civilization of human society is a history that full of continuous innovation and creation $[10,11]$. In particular, when the era step into the twenty-first century, innovation happened in many science and technology fields is deeply changing the constitution of human civilization as well as its core concepts, and now scientific and technical innovation has become the soul of the progress of knowledge economy [12]. With this trend, the cultivation of creative science and technology talents, who as the subject in scientific and technical innovation activities, is also becoming a common focus concerned by many countries in the development of human resources [9].

\subsection{Innovator}

The earliest research can be traced back to the age when British psychologists studied the thinking characteristics of famous geniuses in their book "Hereditary and Genius" and tried to understand the genetic factors of creative expression [13]. Later, Cattell used statistical methods to study the personality traits of American scientists [14]; Chassell et al. examined creativity through psychometric related methods [15]; Joseph conducted a questionnaire survey and performed a systematic study of 710 inventors [16]; Graham studied creativity through scientific discoveries or creative inventions [17]; Anne used various method and studied the intellectual characteristics of physicists, biologists, and social scientists [18]. A psychologists published a famous speech titled "Creativity" and called on psychologists to join hands to carry out research on creative issues [13]. This has led to the trend of cultivating innovative talents in the psychology community. Related research topics include the following directions: The first is to examine the quality or ability related to innovation (or creation) from the perspective of cognitive models, and it is believed thinking activities and knowledge are the basis of innovation (or creation) activities. The second is to examine the quality or ability related to innovation (or creation) activities from the perspective of social psychology. It is believed that the source of creativity is related to personality traits, motivation and social and cultural environment. The third is to examine the quality of innovation (creation) subjects from a comprehensive perspective, and it is believed that creativity is produced by a combination of factors [19].

\subsection{Innovative Education}

After entering the 1990s, the knowledge economy has developed rapidly. Scientific and technological innovation has become an important engine for economic and social development [20, 21]. Education development has become a priority for many countries in the construction of innovative countries. With this background, and at the same time as the promotion of the educational reform movement in this period, more and more researchers are beginning to realize that creative education that focuses on creating skills and thinking training is to cultivate students' innovative ability. Taking this as an opportunity, creative education began to transform into innovative education, and gradually developed into a new theoretical form and a new mode of educational practice in the field of contemporary educational research [22-24]. Its basic development trend is manifested in many aspects: the education system has changed from closed and rigid to open and flexible [23]. This open education system aims to strengthen the connection between schools and society and the communication between various parts of the education system, promote the flexible transition between the educated people' learning and work, and shift the education system from authoritarian to decentralized [25]. To enable schools, teachers, and students to enjoy full autonomy, teacher-student relationship changes from authoritative to equality, independence, and democracy; creates a free-growth environment for educated people; pays attention to the cultivation of individuality and interest. The method changes from an indoctrination style to a heuristic style, from focusing on classrooms to changing both inside and outside the classroom, and from single teaching to the combination of teaching and research [26].

\section{Linkage of Social and Biological Gene}

Innovation in different fields is an activity in which many 
elements interact with the environment or conditions of production. It is a process of combining several elements based on specific purposes and giving them concrete behaviors such as shapes, structures, and functions. It is also a process of analyzing information, acquiring ideas from information, and finding the most appropriate solution to the problem. Studies have shown that this process has a higher similarity with biological genetic engineering. Biological genetic engineering is a technology that combines genomes of different origins to synthesize DNA and transfect cells to transform the inherent genetic characteristics of the cells [26, 27]. Likewise, in the innovative process, there are no biological properties such as biological genes or chromosomes, but there is a great similarity between the information flow process of the innovative and biological system regarding the innovative goals of production, processing, engineering and technology, etc. An organism's DNA is an assembly of genetic information, which regulates and governs everything needed for life activities, including quality, character, appearance, and color, etc. Innovators, in particular, are direct directors of the innovative process, thereby regulating and progressing the innovative process. On the other hand, it has been shown that innovators who create innovations have a set of characteristics that distinguish them from other ordinary people.

The major factor that determines the biological properties of an organism is the gene that constitutes the chromosome. The goal is to raise the social genes specific to the innovator-like biological gene and a model of its relevance (see Figure 1). As shown in Figure 1, living organisms (plants, animals, microbe, etc.) have biological genes as basic units of genetic material, and the regular arrangement of these genes leads to the formation of chromosomes. The chromosomes formed regulate all the functions of life through the expression of genes, and this process is a unique feature of life organism. In other words, living body is maintained and activated by genes, and all the characteristics of living body is governed and determined by genes. On the other hand, applying these biological laws to innovators can reflect innovator characteristics in a very similar way. Innovator has a basic unit of innovation-specific genes called the innovation gene, and the innovative chromosomes are formed through absorption, processing and combination of these innovative genes. The innovative chromosomes formed represent unique chromosomal characteristics of the innovator and the practice process is a unique expression process specific to the innovator. As a result, all the characteristics of the innovator are governed and determined by the innovative genes.

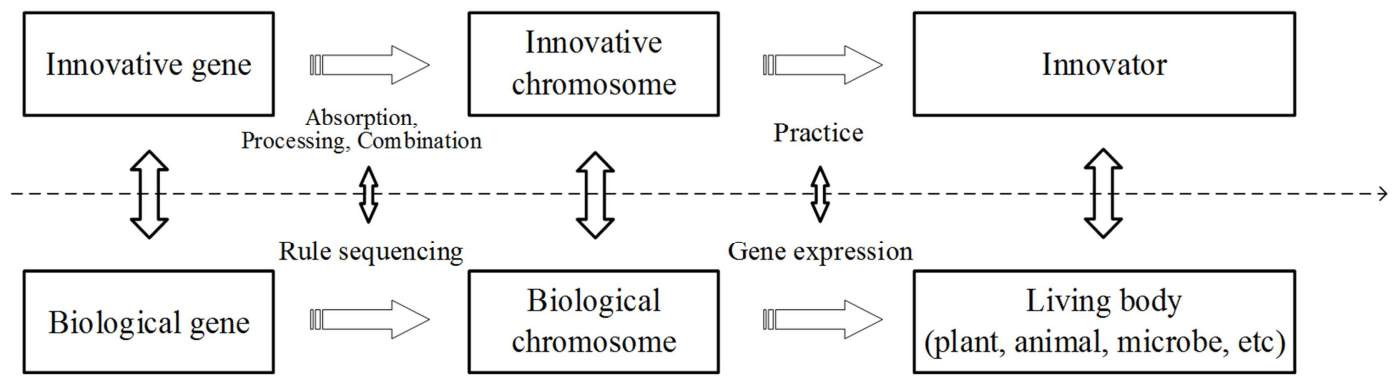

information flow, energy flow

Figure 1. Innovation gene and innovation chromosome.

\section{Construction of Innovative Genetic Model}

\subsection{An Iceberg-Model-Based Innovative Genetic Model}

Competency model refers to a combination of different competency and quality elements needed to be competent for a certain job and achieve a certain performance goal. It is a series of competency and quality features that are combined to meet specific job requirements, including knowledge, skill level, and motivation, personality characteristics, self-image and social role characteristics, etc. At present, the iceberg model is a widely used competency model [12]. The iceberg competency model divides the individual's quality into "above water surface" benchmark quality and "below water surface" discriminatory quality. It describes the individual's quality as an iceberg floating on the ocean, where knowledge and skills belong to the surface part exposed to the surface of the water [11]. This part is the requirement for the basic qualities of the incumbent (Figure 2) [28, 29].

The innovative genetic model based on the iceberg model considers human characteristics, including knowledge, skill level, and motivation, personality characteristics, self-image and social role characteristics, etc., as chromosomes such as biological chromosomes. Ultimately, as biological chromosomes contain a large number of biological genes, the innovator's innovative chromosomes also contain many innovative genes. These innovative genes are unique to innovator, and unlike those of ordinary people, they reflect the proprietary nature of innovator.

The innovative genetic model based on the iceberg model is new model that expresses the individual characteristics of the iceberg model as innovative chromosomes and describes the unique characteristics of innovator through innovative genes that form innovative chromosomes. In the following section, it is described in 
details how to collect and form innovative genes and innovative chromosomes that are important factors in

constructing innovative genetic model.

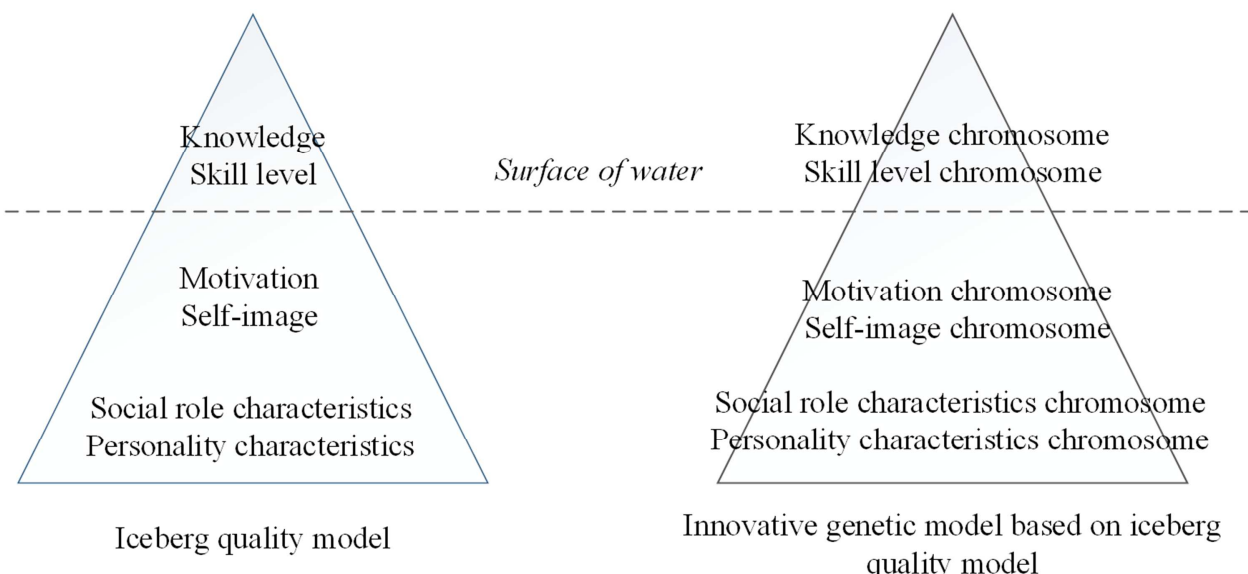

Figure 2. Innovative genetic model based on iceberg quality model.

\subsection{Innovative Gene Collection}

Organism formation is based on the genes that constitute the chromosomes of cells as a template. First, RNA is formed through DNA transcription, and then various amino acids required for the synthesis of the desired proteins are carried by RNA to complete the expression of genetic information and finally form a complete organism $[25,26]$. Likewise, innovator also depends on the innovative genes that make up the innovative chromosome. Accurate collection of these innovative genes is an important factor in establishing the innovative genetic model.

As mentioned earlier, the innovative genes are the basis of the innovative genetic model, so the collection of the innovative genes is the key to building the innovative genetic model. There are many ways to collect data in the process of constructing quality models, such as behavioral event interviews, key event methods, questionnaire surveys, panel discussions, work analysis methods, evaluation methods, expert system databases, focus interviews, and direct observation method etc. These methods have different characteristics. The choice of which method to use to obtain information depends on the actual situation of model. Sometimes, it is necessary to apply several methods at the same time, or to use different methods according to different research phases to complement each other. The collection of innovative genes is an important factor in ensuring the accuracy of innovative genetic model and has a great influence on the classification and formation of the innovative chromosome. Thus, selecting a reasonable collection method and improving the accuracy of the model is a prerequisite for the construction of an innovative genetic model.

\subsection{Innovative Chromosome Formation}

Through the extraction of relevant innovative genes, vast amounts of innovative gene data can be formed. At this time, various methods need to be used for classification and screening, and genes that are strongly related to the purpose of innovation should be selected to exclude the interference of weakly affected genes, thereby forming the innovative chromosomes (see Figure 3).

The selection of methods for the formation of innovative chromosomes is also a prerequisite for ensuring the accuracy of the innovative genetic model. An important problem in forming innovative chromosomes for the collected innovative genes is to accurately form innovative chromosomes by applying appropriate classification and screening methods. Figure 3 shows the innovative genetic model for innovator and shows the results of the innovative genetic model according to the collection method of the innovation gene and the formation method of the innovation chromosome mentioned above.

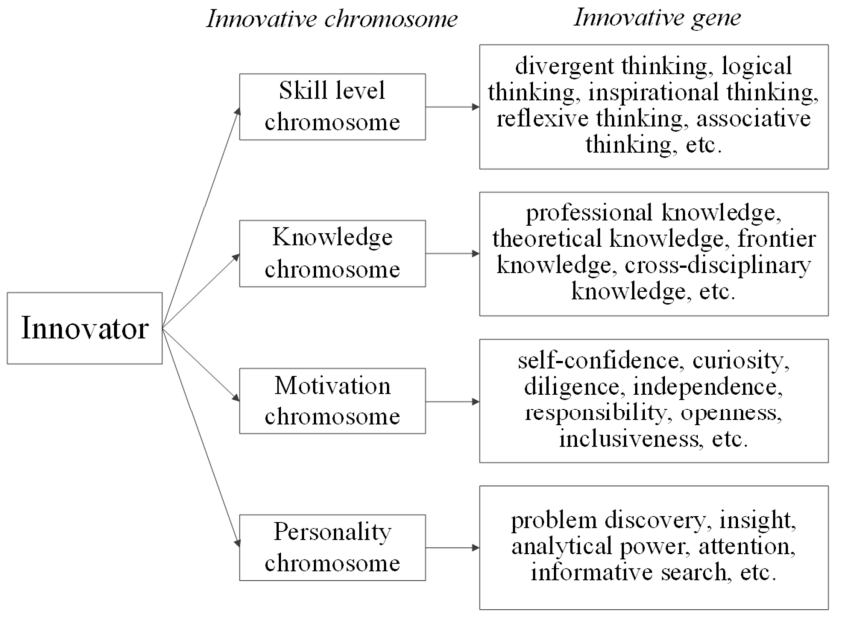

Figure 3. Innovative genetic model of innovator.

Innovative genes included in skill level chromosomes are not only necessary for producing innovative performance expressed mainly in innovators, but also have relatively common characteristics. It shows that the innovator's thinking includes not only rational thinking forms such as analogical thinking, philosophical thinking, and reverse thinking, but also irrational thinking forms such as intuition 
thinking and inspiration thinking. Because the innovative genes of skill level chromosomes have the ability to select, break through, and reconstruct the existing knowledge, experience, and information in the process of innovation, and grasp the important role of the inherent nature and laws of the development of things with the new cognitive model, they can be viewed as intelligent system for individual innovative activities.

\subsubsection{Knowledge Chromosome}

The innovative genes included in the knowledge chromosome are mainly the theoretical knowledge, professional knowledge, and cross-disciplinary knowledge, etc. These are the basic systems for innovators to innovate, showing that innovation requires a sufficient knowledge base and a reasonable knowledge structure as a support. The knowledge chromosome is the premise of the innovative formation, but also the "source of water" of innovative activities.

\subsubsection{Motivation Chromosome}

The innovative genes included in the motivation chromosome are mainly the personality characteristics of the innovators in their professional activities, such as self-image, social motivation, personal attitudes, values, and internal driving forces, etc. In the innovative genetic model based on the iceberg model, these genes are hidden below the surface and difficult to detect, but they are often the main internal factors that affect the innovative performance and the individual behavior of the innovative subject. It plays a decisive role in obtaining or using a particular knowledge and skill. The innovative genes of motivation chromosome are the basic element of the innovator's innovative consciousness and the formation of the innovative spirit.

\subsubsection{Personality Characteristics Chromosome}

The innovative genes included in the personality characteristics chromosome are mainly the characteristics of commonalities that are manifested in problem discovery, problem analysis, and problem-solving in which innovators engage in scientific research or technological development activities. It includes both cognitive ability based on knowledge, experience, and thinking level, such as analysis power, reasoning power, comprehension power, insight, etc., as well as its ability to transform scientific research ideas or scientific research programs into actual scientific and technological achievements. Genes such as operational skills, teamwork, and experience migration, which constitute the key link for effective and smooth implementation of technological innovations, can be seen as an individual's implementation system for technological innovation.

\section{Genetic Model and Education}

\subsection{Innovative Chromosomes Promotes Innovative Ideas}

In the process of forming the innovative ideas, each chromosome represents a dimension, and the dimensions of the innovative ideas can be determined based on the number of innovative chromosomes formed. An important factor in promoting the innovative ideas is innovation courage. The model in Figure 4 shows the innovator's chromosome and explains the pattern that drives the innovative ideas. The key chromosomes forming the innovative ideas are skill level chromosome, personality characteristics chromosome, knowledge chromosome, and motivation chromosome are the catalysts of skill level chromosome. As shown in model, it is suggested that increasing skill level ability will enhance your ability to form the innovative ideas.

The innovative genetic model that promotes innovation is a model showing the relationship of the innovative chromosomes after forming the innovative chromosomes based on collecting the innovative genes specific to innovator. This model shows to what people should do to promote innovation and what the key factors are for it (innovative chromosome and innovative gene).

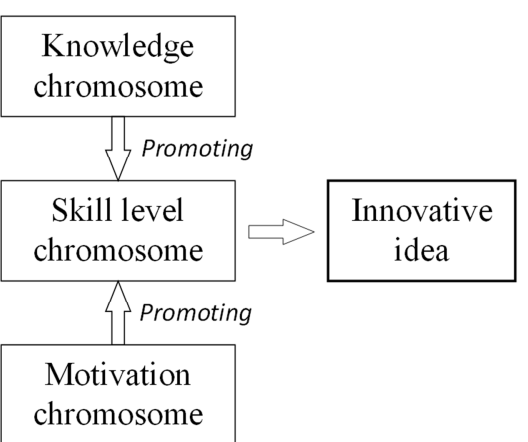

Figure 4. Innovative chromosome promotes innovative idea.

\subsection{Education Promotes Innovation}

Innovative education is an education form based on the needs of human and social development [30]. It aims at cultivating people with innovative qualities such as innovative consciousness, innovative thinking, innovative ability, and sound personality, etc. Innovation quality refers to the total of the innovative genes that constitute innovative chromosomes specific to innovators, which are the main components of the innovative genetic model proposed above. Because the innovator's quality constitutes a multi-dimensional organic system, cultivation of innovators 
can effectively reach the goal by integrating skill level, personality characteristics, knowledge, and motivation education (Figure 4). The innovative genes and the innovative chromosomes that are specific to innovator can improve and enhance his or her abilities through education. This education is the innovative education, and as shown in the innovative genetic model promoting innovation, it suggests that innovative education is an important factor to enhance or improve people's innovative ability.

\section{Conclusion}

In recent years, with the in-depth study of the entire innovator and the development of the times, the definition and attributes for innovator have undergone a gradual process of dynamic evolution. Recently, many models have been proposed to explain the unique characteristics of the innovator and attempts have been made to verify their accuracy through several methods. In this paper, some concepts were introduced including the social genes and chromosomes specific to the innovator equivalent to biological genes and chromosomes by combining biological genetic theory with innovative theory and a genetic model was presented that characterizes innovators. By using innovative genes and innovative chromosomes to evaluate the characteristics specific to innovator, the essential characteristics of human beings were explained using biological genetic theory. The proposed model should be further validated through a number of surveys, but it provides a rationale for the relationship between innovators and innovative genes, and the innovative genes and chromosomes that play an important role in raising the innovative ideas.

\section{Acknowledgements}

This work was partially supported by National Natural Science Foundation of China (No. 71573065, No. 71571085).

\section{References}

[1] K. Z. Chen, X. A. Feng, and X. C. Chen, Reverse deduction of virtual chromosomes of manufactured products for their gene-engineering-based innovative design. CAD Computer Aided Design, 2005, 37 (11), 1191-1203.

[2] Y. T. Fu and S. J. Luo, Style perception-oriented product family shape gene design. Computer Integrated Manufacturing System, 2012, 18 (3), 449-457.

[3] C. Jiang, Y. L. Yu, and Y. S. Huai, Product innovation design method based on pan-ethnic group design gene. Applied mechanics and Materials, 2013, 365-366, 1251-1254.

[4] Z. Y. Wang, S. F. Wu, and H. B. Qin, Research on stacker's variant design based on gene model. Advanced Materials Research, 2011, 215, 351-355.

[5] Y. X. Feng, Y. C. Gao, and Z. Y. Mai, Assembly model and design thinking: A study of assembly scheme based on gene model. Assembly Automation, 2013, 33 (3), 272-281.

[6] X. J. Liu, Y. Sun, and J. F. Wu, Product's gene regulatory network model and its aiding to design process. Computer Integrated Manufacturing Systems, 2013, 19 (7), 1463-1471.

[7] D. J. Teece, Profiting from technological innovation: implications for integration, collaboration, licensing and public policy, Research Policy, 2014, 15 (6), 285-305.

[8] P. S. Aithal, An innovative education model to realize ideal education system, international journal of scientific research and management, 2015, 3 (3), 2464-2469.

[9] J. Pereira and T. Murzyn, Integrating the "new" with the "traditional": An innovative education model, Journal of Palliative medicine, 2001, 4 (1), 31.

[10] C. Freeman, L. Soete, The economics of industrial innovation, MIT Press, 1997, 7 (2), 215-219.

[11] A. R. Boyatzis, The competent manager : A model for effective performance. New York, John Wiley, 1982, 20-21.

[12] L. M. Spencer Jr. and S. M. Spencer, Competence at work: Model for performance. New York: John Wiley and Sons, 1993, 132-133.

[13] F. Galton, Hereditary genius: An inquiry into the consequences. New York, Appleton, 1869.

[14] M. K. Cattell, Statistics of American psychologists, American Journal of Psychology, 1903, 14 (6), 310-328.

[15] L. M. Chassell, Tests for originality, Journal of Educational Psychology, 1916, 7 (6), 317-328.

[16] R. Joseph, The psychology of inventor: A study of the patentee. Washington, DC: Inventor press, 1931.

[17] W. Graham, The art of thought. London, C. A. Watts, 1945.

[18] R. Anne, The making of a scientist. New York: Dodd Mead, 1952.

[19] J. P. Guilford, Three faces of intellect. American Psychologist, 1959, 14 (8), 469-479.

[20] M. V. Klarin, Conceptual challenges in understanding innovative education in organizational context, International Journal of Cognitive Research in science, Engineering and Education, 2010, 4 (1), 67-71.

[21] J. J. Yue and L. J. Feng, The empirical research for taking technology innovation genes and forming chromosomes based on coal-bed gas mining, 2016 Global Congress on Manufacturing and Management, Procedia Engineering 174 (2017), 227-231.

[22] X. J. Liu, Y. Sun, and J. F. Wu, Gene regulatory network model for product industrial design, Journal of Theoretical and Applied Information Technology, 3013, 48 (3), 1606-1611.

[23] H, James. J. Donnelly, and M. John, A methodology for identifying innovator characteristics of new brand purchasers, Journal of Marketing Research, 1974, 11 (3), 331-334.

[24] H. Katharina, N. Martina, and G. G. Han, Motivation and commitment in innovation management-personal characteristics of innovators, International Journal of Innovation Management, 2011, 12-34. 
[25] A. Griffin, R. Price, M. Maloney, and B. Vojak, Voices from the field: How exceptional electronic industrial innovator, Journal of product Innovation management, 2009, 26, 222-240.

[26] M. A. Glynn, Innovative genius: a framework for relating individual and organizational intelligences to innovation. Academy of management Review, 1996, 21, 4, 1081-1111.

[27] H. G. Gemunden, S. Salomo, and K. holzle, Role models for radical innovations in times of open innovation. Creativity and Innovation Management, 2007, 16, 408-421.
[28] W. John and J. Loy, Social psychological characteristics of innovators, American Sociological Review, 1969, 34 (1), 73-82.

[29] N. Martina and H. Katharina, Personal characteristics of innovators: An empirical study of roles in innovation management, International Journal of innovation management, 2010, 14 (6), 1129-1147.

[30] J. M. Howell, C. M. Shea, and C. A. Higgins, Champions of product innovation: defining, developing, and validating a measure of champion behavior. Journal of Business Venturing, 2005, 20, 641-661. 